\title{
CURVAS DE DOSE-RESPOSTA DE BIÓTIPOS RESISTENTE E SUSCETÍVEL DE Bidens pilosa L. AOS HERBICIDAS INIBIDORES DA ALS
}

\author{
Pedro Jacob Christoffoleti \\ Depto. de Produção Vegetal - USP/ESALQ, C.P. 9 - CEP: 13418-900 - Piracicaba, SP. \\ Bolsista CNPq.e-mail <pjchrist@esalq.usp.br>
}

\begin{abstract}
RESUMO: A resistência de plantas daninhas aos herbicidas é um fenômeno de ocorrência mundial, sendo caracterizada como uma redução na resposta de uma população a produtos químicos, em sua dose recomendada, como resultado de sua aplicação sucessiva. O número de casos de resistência registrados no Brasil tem aumentado significativamente nos últimos anos, porém poucos estudos científicos têm sido feitos para elucidar este fenômeno. Sendo assim, foram conduzidos experimentos com o objetivo de elaboração de curvas de doseresposta comparativa entre dois biótipos da planta daninha picão-preto (Bidens pilosa L.), sendo um resistente (R) e outro suscetível (S) aos herbicidas inibidores da ALS. Para isso, foram utilizados três herbicidas do grupo químico das sulfoniluréias e um do grupo químico das imidazolinonas. No estádio de três a quatro pares de folhas, as plantas $\mathrm{R}$ e $\mathrm{S}$ de $B$. pilosa foram pulverizadas com os herbicidas chlorimuron-ethyl, metsulfuronmethyl, nicosulfuron e imazethapyr, em doses correspondentes a múltiplos de 0,$0 ; 0,001 ; 0,01 ; 0,1 ; 1,0 ; 10 ; 100$ e 1000 vezes a dose recomendada para aplicação de campo. A partir dos resultados da porcentagem de fitotoxicidade foi feito o ajuste das curvas de dose-resposta. As relações entre o $C_{50}$ do biótipo resistente e o $C_{50}$ do biótipo suscetível (R/S) foram de 40,92 ; 173,$84 ; 57,47$ e 57,16 para os herbicidas chlorimuron-ethyl, nicosulfuron, metsulfuron-methyl, e imazethapyr, respectivamente. O biótipo $\mathrm{R}$ de $B$. pilosa apresenta elevado nível de resistência cruzada aos herbicidas inibidores da ALS, do grupo químico das sulfoniluréias e imidazolinonas.
\end{abstract}

Palavras-chave: planta daninha, resistência aos herbicidas, sulfoniluréia, imidazolinona

\section{RATE-RESPONSE CURVES OF RESISTANT AND SUSCEPTIBLE Bidens pilosa L. BIOTYPES TO ALS-INHIBITOR HERBICIDES}

\begin{abstract}
Weed herbicide resistance is a phenomenon defined as a response reduction of a population to a chemical product sprayed at a recommended rate, as a result of its continuous application. The incidence of herbicide-resistant weeds in Brazil has increased lately, but few scientific studies have been conducted to elucidate the phenomenon. In this regard, experiments aiming to build rate-response curves comparing a resistant $(R)$ and a susceptible (S) biotype of the weed Bidens pilosa L., to ALS inhibitor herbicides, were set up. At the stage of three to four leaves, biotypes $\mathrm{R}$ and $\mathrm{S}$ of $B$. pilosa were sprayed with the herbicides chlorymuron-ethyl, metsulfuronmethyl, nicosulfuron and imazethapyr, at multiples of $0.0 ; 0.001,0.01,0.1 ; 1.0 ; 10 ; 100$ and 1,000 of the recommended field rates. Results lead to the building of percentage control rate-response curves. The ratio between the $C_{50}$ of the resistant biotype, divided by the $C_{50}$ of the susceptible biotype, were $40.92 ; 173.84 ; 57.47$ and 57.16 for the herbicides chlorymuron-ethyl, nicosulfuron, metsulfuron-methyl and imazethapyr, respectively. The $\mathrm{R}$ biotype of $B$. pilosa had a high degree of resistance in relation to all ALS inhibitor herbicides studied, being also cross resistant to imidazolinone and sulfonylurea.

Key words: weed, herbicide resistance, sulfonylurea, imidazolinone
\end{abstract}

\section{INTRODUÇÃO}

A comprovação científica da resistência de populações de plantas daninhas aos herbicidas pode ser feita através de ensaios de campo, casa-de-vegetação e laboratório. Ryan (1970) foi o primeiro pesquisador a publicar dados referentes à comprovação científica de resistência aos herbicidas inibidores do fotossistema II. Populações da planta daninha Senecio vulgaris, infestantes de viveiros comerciais de mudas de pinus tratadas durante 11 anos consecutivos com herbicidas do grupo químico das triazinas, não eram mais controladas satisfatoriamente por estes herbicidas. A partir de sementes coletadas desta área, e de áreas onde estes herbicidas nunca tinham sido aplicados como forma de controle da planta daninha S. vulgaris, Ryan (1970) desenvolveu um protocolo de casa-de-vegetação para comprovação científica da resistência da planta daninha aos herbicidas do grupo químico das triazinas.

A comprovação da resistência de biótipos de plantas daninhas aos herbicidas através de experimentos de casa-de-vegetação apresenta diversas vantagens em relação a outros métodos científicos de detecção, porém existem aspectos negativos de seu uso (Truelove \& Hensley, 1982). Dentre as desvantagens, destaca-se que os mecanismos de resistência das plantas não são 
determinadas por este tipo de experimento, adicionado ao fato de que a sua condução é demorada. Por outro lado, como vantagens, evidencia-se a possibilidade de teste de um grande número de plantas, além de não ser necessário o uso de mão-de-obra especializada na instalação dos testes. Apesar das desvantagens, esta metodologia de teste da resistência de biótipos de plantas daninhas a herbicidas está sendo usada como indispensável na comprovação científica, complementando os resultados de campo e laboratório.

Através da curva de dose-resposta, é determinado o índice $\mathrm{C}_{50}$, ou seja, a dose de herbicida necessária para controlar $50 \%$ da população. Este índice é usado para comparação entre os biótipos resistentes e suscetíveis. O uso de regressão não linear descrito por Streibig et al. (1993) é o método mais adaptado para elaboração de curva de dose-resposta entre herbicida e planta daninha. Uma adaptação desse modelo e de outros originalmente apresentados na literatura foi proposta por Seefeldt et al. (1995). Esses autores sugerem que o modelo log-logístico apresenta inúmeras vantagens em relação a outros métodos de análise. A principal delas é que um dos termos integrantes da equação não linear é o $C_{50}$, facilitando assim a comparação do nível de resistência dos biótipos testados. Desta forma, o modelo log-logístico pode ser preferencialmente utilizado nas determinações de curvas de dose-resposta de plantas daninhas a herbicidas (Seefeldt et al., 1995). Na literatura existem diversos trabalhos que procuram determinar a relação entre $\circ C_{50}$ do biótipo resistente e $\circ C_{50}$ do biótipo suscetível, quantificando assim a resistência de biótipos de plantas daninhas aos herbicidas inibidores da ALS (Hall et al., 1998; Boutsalis \& Powles, 1995; Chaves et al., 1997; Friesen et al., 1993). Para isso podem também ser usadas curvas de crescimento comparativas, descritas por Causton et al. (1978) e Hunt (1982); e assim elaborar modelos matemáticos de estudos de diferenciação entre os biótipos $\mathrm{R}$ e $\mathrm{S}$ (France \& Thornley, 1984).

Os valores de $\mathrm{C}_{50}$ têm sido usados não apenas nos estudos de caracterização de resistência de biótipos de plantas daninhas, mas também na determinação da seletividade de variedades tolerantes de cultivos, comparadas com variedades não melhoradas para essa característica. Pornprom \& Yong (1997) utilizaram a metodologia do $C_{50}$ para estudo da tolerância de cultivares melhorados de pimenta. As bases fisiológicas da seletividade dos herbicidas nicosulfuron e primisulfuron foram determinadas por Carey et al. (1997), sendo que a sensibilidade diferencial de cinco espécies de plantas foi determinada através dos valores de $C_{50}$. Hart et al. (1993) conduziram estudos em casa-devegetação e laboratório para determinar o grau de dominância monogênica de variedades de beterraba açucareira resistente aos herbicidas do grupo químico das sulfoniluréias, comparando beterraba diplóide homozigota e heterozigota. Determinaram o $\mathrm{C}_{50}$ através de doses crescentes dos herbicidas primisulfuron, thifensulfuron e chlorimuron-ethyl.

Lovell et al. (1996) testaram a resistência de biótipos das plantas daninhas Kochia scoparia e Xanthium strumarium provenientes de áreas tratadas com herbicidas inibidores da ALS na região oeste dos Estados Unidos. Dentre os testes "in vivo" efetuados, foram determinadas curvas de dose-resposta dos biótipos resistentes e suscetíveis. A partir das equações utilizadas para representar os dados foi possível determinar $0 \mathrm{C}_{50}$ das populações e diferenciar, assim, o nível de resistência entre as populações. O biótipo de Kochia scoparia proveniente do estado de Idaho apresentou uma relação $\mathrm{C}_{50}$ (resistente)/ $\mathrm{C}_{50}$ (suscetível) de 160 , sendo que para o biótipo proveniente de Montana, esta relação foi de 170 .

No Brasil, o primeiro relato sobre o uso do $C_{50}$ como forma de comprovação e determinação do nível de resistência de um biótipo de planta daninha foi feito por Christoffoleti et al. (1996). Foram conduzidos diversos experimentos em condições de casa-de-vegetação, utilizando biótipos resistentes e suscetíveis de Bidens pilosa, e doses crescentes de herbicidas inibidores da ALS. $O C_{50}$ foi determinado para os herbicidas imazethapyr, nicosulfuron, metsulfuron-methyl e chlorimuron-ethyl, que baseado nos resultados de fitomassa coletada 21 dias após a aplicação dos herbicidas, foram 370, 39, 26 e 12 vezes maior para o biótipo resistente, comparado com o biótipo suscetível, respectivamente.

O objetivo deste experimento foi caracterizar o nível de resistência de um biótipo da planta daninha Bidens pilosa aos herbicidas inibidores da ALS, em condições de casa-de-vegetação, através de curvas de dose-resposta.

\section{MATERIAL E MÉTODOS}

As sementes de $B$. pilosa supostamente resistente foram obtidas de uma área localizada no município de São Gabriel do Oeste, no Estado de Mato Grosso do Sul (longitude $54^{\circ} 33^{\prime} \mathrm{W}$ e latitude de $19^{\circ} 56^{\prime}$ S), em uma propriedade cultivada com soja, na qual herbicidas inibidores da ALS tinham sido aplicados por pelo menos oito anos sucessivos. No entanto, nas safras 93/94 e 94/95, foram observadas falhas no controle do picão-preto por estes herbicidas em alguns talhões da propriedade. Na safra 95/96, foi escolhido um dos talhões onde ocorreram falhas de controle para coleta de sementes.

Para a coleta das sementes suscetíveis foram escolhidas plantas de uma área localizada aproximadamente $25 \mathrm{~km}$ de distância do talhão, dentro da cidade de São Gabriel do Oeste, MS. Nessa área, existia uma horta comunitária há muitos anos, onde com certeza os herbicidas inibidores da ALS nunca tinham sido 
aplicados, bem como a área era isolada completamente daquelas com suspeita de resistência. Essa população de plantas daninhas foi considerada como suscetível e procedente da mesma região geográfica.

Foram escolhidas, no mínimo, 50 plantas, sadias e com sementes maduras, de onde foram coletadas aproximadamente $100 \mathrm{~g}$ de sementes. Procurou-se coletar aproximadamente a mesma quantidade de sementes de cada planta, ou seja, no mínimo 20 inflorescências de cada uma. As sementes foram, então, acondicionadas em sacos de papel, para posterior transporte até o laboratório do Departamento de Produção Vegetal da USP/ESALQ, onde foram armazenadas em local seco e temperatura ambiente, aguardando o momento da instalação dos experimentos.

No dia 15/03/97, foram plantadas 10 sementes de cada biótipo da planta daninha $B$. pilosa resistente $(R)$ e suscetível (S) aos herbicidas inibidores da ALS. As sementes foram semeadas a $1 \mathrm{~cm}$ de profundidade em vasos de $12 \mathrm{~cm}$ de diâmetro, contendo uma mistura de solo e terra vegetal. Os vasos foram colocados em casade-vegetação e as plantas foram irrigadas diariamente. Quatorze dias após o plantio, cada vaso foi desbastado para quatro plantas por vaso para os biótipos R e S.

Os herbicidas foram aplicados quando as plantas de $B$. pilosa apresentavam-se no estádio de três a quatro pares de folhas, 15 dias após o plantio. A aplicação foi feita com pulvrizador pressurizado com ar comprimido na pressão de $207 \mathrm{kPa}$, em câmara de aspersão, utilizando uma ponta de pulverização do tipo Teejet $11002 \mathrm{E}$, com jato de distribuição uniforme. O volume de calda utilizado nas aplicações de todos os tratamentos foi de 200 Lha $^{-1}$. A aplicação iniciou-se às $8 \mathrm{~h} 00$ e terminou às $12 \mathrm{~h} 30$, quando a temperatura ambiente era de $27^{\circ} \mathrm{C}$ e umidade relativa do ar de $70 \%$. Após a aplicação dos herbicidas, os vasos foram colocados em casa-de-vegetação, e somente foram irrigados no dia seguinte, garantindo assim a absorção foliar do herbicida.

Os tratamentos utilizados no experimento consistiram de quatro herbicidas, sendo três sulfoniluréias (chlorimuron-ethyl - contendo $750 \mathrm{~g} \mathrm{~L}^{-1}$, metsulfuron-methyl - contendo $750 \mathrm{~g} \mathrm{~L}^{-1}$, e nicosulfuron contendo $750 \mathrm{~g} \mathrm{~L}^{-1}$ ), e uma imidazolinona (imazethapyr contendo $750 \mathrm{~g} \mathrm{~L}^{-1}$ ). As doses utilizadas para cada herbicida seguiram uma escala logarítmica, a partir da dose recomendada, ou seja, 0,$0 ; 0,001 ; 0,01 ; 0,1 ; 1,0 ; 10$; 100 e 1.000 vezes a dose recomendada, equivalendo para o chlorimuoron-ethyl a $0 ; 0,02 ; 0,2 ; 2 ; 20 ; 200,2.000$ e 20.000 g i.a.ha ${ }^{-1}$; para o nicosulfuron a 0,$0 ; 0,005 ; 0,05$; 0,$5 ; 5 ; 50 ; 500$ e 5.000 g i.a. ha ${ }^{-1}$; para o metsulfuronmethyl a 0,$0 ; 0,003 ; 0,03 ; 0,3 ; 3 ; 30 ; 300$ e 3.000 g i.a. $\mathrm{ha}^{-1}$, e para o imazethapyr a 0,$0 ; 0,1 ; 1 ; 10 ; 100 ; 1.000$; 10.000 e $100.000 \mathrm{~g}$ i.a. ha ${ }^{-1}$. Em todos os tratamentos herbicidas, foi adicionado surfactante não iônico, na dose de $0,25 \% \mathrm{v} / \mathrm{v}$.

Scientia Agricola, v.59, n.3, p.513-519, jul./set. 2002
Vinte e um dias após a aplicação dos herbicidas, foram feitas as avaliações visuais de fitotoxicidade dos herbicidas. A fitotoxicidade foi baseada no vigor, e clorose da planta, comparada com a testemunha, sendo atribuído $0 \%$ quando não existia efeito fitotóxico do herbicida, ou seja, a parcela tratada era semelhante à testemunha sem herbicida, e 100\% quando as plantas da parcela estavam completamente mortas.

Os resultados da avaliação visual de fitotoxicidade foram inicialmente submetidos à análise de variância, na qual as doses foram consideradas variáveis independentes, com o objetivo de observar se o aumento da dose de herbicida resultou em efeito significativo na resposta das plantas, e servindo de base para o teste de precisão no ajuste do modelo não linear. Em seguida, os dados foram analisados utilizando modelos não lineares de ajuste de uma curva de dose-resposta. A relação entre doses de um herbicida e a respostas das plantas é de fundamental importância para o entendimento de diversos aspectos relacionados com a seletividade e eficácia dos herbicidas. Para isso, diversos métodos têm sido usados; porém, para esta pesquisa utilizou-se o modelo proposto por Seefeldt et al. (1995).

A equação matemática (Seefeldt et al., 1995), que relaciona a resposta da planta com a dose $\mathrm{x}$ do herbicida é a seguinte:

$$
\mathrm{y}=\mathrm{f}(\mathrm{x})=\mathrm{C}+\frac{\mathrm{D}-\mathrm{C}}{1+\left(\frac{\mathrm{x}}{\mathrm{C}_{50}}\right)^{\mathrm{b}}}=\mathrm{C}+\frac{\mathrm{D}-\mathrm{C}}{1+\exp \left(\mathrm{b}\left(\log (\mathrm{x})-\log \left(\mathrm{C}_{50}\right)\right)\right)}
$$

Onde: $D=$ limite superior da curva; $C=$ limite inferior da curva; b=declividade da curva, e $\mathrm{C}_{50}=$ dose correspondente a $50 \%$ de resposta. O limite superior da curva $\mathrm{D}$ corresponde à resposta média da testemunha e o limite inferior da curva $C$ é a resposta média com doses altas de herbicida. $O$ parâmetro $b$ descreve $a$ declividade da curva em torno do $\mathrm{C}_{50}$.

Para ajuste da equação e obtenção dos parâmetros estatísticos os dados foram submetidos a análise de regressão não linear. Valores iniciais de $D, C$ e $C_{50}$ foram utilizados [(modelo proposto por Seefeldt et al. (1995))] para que as iterações fossem executas e assim obter as melhores estimativas através da combinação desses valores. Para estimativa dos valores iniciais examinou-se a tendência dos valores originais em gráfico e assim foi possível visualizar os valores iniciais de $\mathrm{C}, \mathrm{D}$ e $\mathrm{C}_{50}$. Para os valores de $\mathrm{b}$ foram feitas diversas tentativas com valores variando entre 1 e 6 .

A partir das equações, foram construídos gráficos, usando a escala logarítmica para as doses do herbicida (variável independente). Para a porcentagem de fitotoxicidade em relação à testemunha (variável dependente) foi empregada escala linear. 


\section{RESULTADOS E DISCUSSÃO}

A análise de variância conjunta dos dados de porcentagem de fitotoxicidade dos dois biótipos (R e S) foi significativa para os quatro herbicidas, mostrando efeito dos tratamentos. Quando as curvas de dose-resposta de dois biótipos ( $R$ e $S$ ) de uma mesma espécie de planta daninha, a determinado herbicida, são paralelas, é indicação que a causa da resistência do biótipo $\mathrm{R}$ é decorrente da menor afinidade do herbicida ao seu sítio de ação (Streibig et al., 1993). Quando as curvas não são paralelas, o mecanismo de resistência envolve outros fatores adicionais à modificação do local de ação. Inicialmente, optou-se por analisar os resultados de porcentagem de fitotoxicidade fazendo-se o teste de paralelismo, para verificar se as curvas dos biótipos, dentro de cada herbicida, são paralelas, ou seja, apresentam o mesmo valor de $b$ (declividade da curva no ponto de inflexão). $O$ teste $F$, que verifica a precisão dos ajustes paralelos e não paralelo, é baseado na soma dos quadrados do resíduo $\left(S Q_{r}^{\prime}\right)$ dos respectivos modelos em relação a $S Q_{r}$ " do modelo geral, de acordo com a seguinte fórmula:

$$
\mathrm{F}=\frac{\frac{\left(\mathrm{SQ}_{\mathrm{e}}^{\mathrm{II}}-S Q_{e}^{I}\right)}{\mathrm{GL}_{\mathrm{e}}^{\mathrm{II}}-G L_{e}^{I}}}{\frac{S Q_{e}^{I}}{G L_{e}^{I}}}
$$

Nenhum dos modelos serve como bom ajuste dos dados nas curvas de dose-resposta, pois a $S_{r}{ }_{r}^{\prime}$ dos modelos paralelo e não paralelo são significativamente superiores à $S_{r}{ }_{r}$ do modelo geral. A principal razão para a baixa precisão dos ajustes é porque foi assumido que os valores de $C$ nos dois modelos seriam os mesmos e próximos de zero. No entanto, para o biótipo resistente, mesmo na dose mais alta, o valor obtido não é menor que $30 \%$. Desta forma, nenhum dos modelos ajusta satisfatoriamente os dados, e assim não foi possível concluir se as curvas são paralelas entre si. No entanto, o intervalo de confiança obtido dos valores de b para os dois biótipos, no ajuste do modelo não paralelo não são coincidentes, indicando assim o possível não paralelismo das curvas (Tabela 1 ).

O teste de paralelismo das curvas de doseresposta comprovou ser pouco indicado para esta pesquisa. A resistência dos biótipos de plantas daninhas aos herbicidas inibidores da ALS são decorrentes de alteração do local de ação (Guttieri et al., 1992; Ponchio et al., 1996; Saari et al., 1990; Shaner, 1991 e Simpson et al., 1995), portanto o teste de paralelismo deveria indicar que as curvas são paralelas. Outro fato que evidencia a baixa precisão deste teste é que o biótipo $R$ de $B$. pilosa utilizada nesta pesquisa foi o mesmo pesquisado por Ponchio (1997), que através de bioensaios 'in vitro', comprovou ser a resistência causada por uma alteração no sítio de ação. Assim, foi feita a análise de regressão não linear para cada biótipo dentro de cada herbicida.

Os resultados dos termos da equação loglogística (parâmetros $\mathrm{C}, \mathrm{D}, \mathrm{C}_{50}$ e b) encontram-se na Tabela 2. Para a análise, foram utilizados os resultados da porcentagem de fitotoxicidade em relação à testemunha. A escala porcentual foi utilizada para satisfazer exigência do modelo log-logístico proposto por Seefeldt et al. (1995). Os valores de D não diferem, quando comparado o biótipo resistente com o biótipo suscetível, dentro de cada herbicida; no entanto, os valores de $C$ diferem entre si. As equações ajustaramse de forma bastante precisa, pois os valores de $R^{2}$ foram bastante próximo de um, explicando mais de $90 \%$ da variabilidade dos dados entre as diversas doses dos herbicidas. Em todos os herbicidas, os ajuste da curva de dose-resposta para o biótipo resistente foi de precisão inferior ao biótipo suscetível (Tabela 2).

Tabela 1 - Valores de b (declividade da curva) e seu intervalo de confiança, obtidos através do modelo de ajuste log-logístico não paralelo, dos dados de porcentagem de fitotoxicidade dos biótipos $\mathrm{R}$ e $\mathrm{S}$ de $B$. pilosa, dos herbicidas chlorimuron-ethyl, nicosulfuron, metsulfuron-methyl e imazethapyr.

\begin{tabular}{|c|c|c|c|c|c|}
\hline \multirow{2}{*}{ Herbicida } & \multirow{2}{*}{ Modelo } & \multirow{2}{*}{ Biótipo } & \multirow{2}{*}{ Valor de b } & \multicolumn{2}{|c|}{ Limite do intervalo de confiança } \\
\hline & & & & inferior & superior \\
\hline \multirow[t]{3}{*}{ Chlorimuron-e thyl } & Não paralelo & $\mathrm{R}$ & 0,37 & 0,31 & 0,42 \\
\hline & & $\mathrm{S}$ & 0,68 & 0,57 & 0,80 \\
\hline & Paralelo & $\mathrm{R}$ e $\mathrm{S}$ & 0,51 & 0,42 & 0,59 \\
\hline \multirow[t]{3}{*}{ Nicosulfuron } & Não paralelo & $\mathrm{R}$ & 0,47 & 0,38 & 0,56 \\
\hline & & $\mathrm{S}$ & 0,95 & 0,75 & 1,16 \\
\hline & Paralelo & $R$ e $S$ & 0,64 & 0,53 & 0,76 \\
\hline \multirow[t]{3}{*}{ Metsulfuron-methyl } & Não paralelo & $\mathrm{R}$ & 1,60 & 1,19 & 0,67 \\
\hline & & $\mathrm{S}$ & 0,58 & 0,48 & 2,01 \\
\hline & Paralelo & $R$ e $S$ & 0,93 & 0,73 & 1,13 \\
\hline \multirow[t]{3}{*}{ Imazethapyr } & Não paralelo & $\mathrm{R}$ & 0,44 & 0,33 & 0,56 \\
\hline & & $S$ & 1,28 & 0,83 & 1,74 \\
\hline & Paralelo & $R$ e $S$ & 0,68 & 0,51 & 0,84 \\
\hline
\end{tabular}


$\mathrm{O}$ valor de $\mathrm{C}$ do chlorimuron-ethyl para o biótipo suscetível é negativo (Tabela 2), o que é irreal, pois não existem resultados de porcentagem de fitotoxicidade negativa. No entanto, para a previsão da dose-resposta, este resultado pode ser considerado normal, pois o intervalo de confiança do valor de $\mathrm{C}$ é suficientemente grande para incluir valores maiores ou iguais a zero.

Para o cálculo dos valores de $C_{50}$ baseado na dose de ingrediente ativo do herbicida, $\circ \mathrm{C}_{50}$ da equação (Tabela 2) foi multiplicado pelas doses recomendadas de ingrediente ativo utilizado, respectivamente 20; 50; 3,0 e $100 \mathrm{~g}$ para os herbicidas chlorimuron-ethyl, nicosulfuron, metsulfuron-methyl e imazethapyr (Tabela 4). Os valores de $C_{50}$ para o biótipo resistente foram superiores ao do biótipo suscetível para os quatro herbicidas estudados, pois os limites dos intervalos de confiança não foram coincidentes para nenhum $\mathrm{C}_{50}$ do biótipo $\mathrm{R}$ e $\mathrm{S}$ dentro de cada herbicida (Tabela 3). Desta forma, a relação $R / S$, que corresponde à divisão do $C_{50}$ do biótipo $R$ pelo $C_{50}$ do biótipo $S$, foi superior a um para os quatro herbicidas, comprovando assim a resistência do biótipo $\mathrm{R}$ de $B$. pilosa aos herbicidas estudados.
O nível de resistência caracterizado pela relação entre $\circ \mathrm{C}_{50}$ do biótipo resistente e $\circ \mathrm{C}_{50}$ do biótipo suscetível é de 40,$92 ; 173,84 ; 57,47$ e 57,16 para os herbicidas chlorimuron-ethyl, nicosulfuron, metsulfuronmethyl, e imazethapyr, respectivamente. Os valores de R/ $S$ representam índices de tolerância do biótipo resistente em relação ao biótipo sucetível para um controle de $50 \%$ e nunca deve ser interpretado que o biótipo resistente tolera R/S mais herbicida que o suscetível. Este índice, portanto serve apenas de comparação entre os biótipos, porque a obtenção destes índices é resultante de dados de casa-de-vegetação e não de campo.

$\mathrm{O}$ biótipo $\mathrm{R}$ de $B$. pilosa apresenta resistência cruzada aos herbicidas inibidores da ALS, ou seja, resistente tanto para as sulfoniluréias (chlorimuron-ethyl, nicosulfuron e metsulfuron-methyl) quanto imidazolinonas (imazethapyr) (Tabela 3).

A partir das equações log-logísticas foram elaborados os gráficos de dose-resposta (Figura 1). As médias dos valores originalmente coletadas no experimento foram também plotadas no gráfico para verificação visual da precisão do ajuste das curvas. A

Tabela 2 - Parâmetros das equações das curvas de dose-resposta com os biótipos resistente (R) e suscetível (S) de $B$. pilosa, aos herbicidas chlorimuron-ethyl, nicosulfuron, metsulfuron-methyl e imazethapyr.

\begin{tabular}{lccrrrc}
\hline \multirow{2}{*}{ Herbicida } & \multirow{2}{*}{ Biótipo } & \multicolumn{7}{c}{ Parâmetro da equação } \\
\cline { 2 - 7 } Chlorimuron-ethyl & $\mathrm{D}$ & $\mathrm{C}$ & $\mathrm{C}_{50}$ & $\mathrm{~b}$ & $\mathrm{R}^{2}$ \\
& $\mathrm{R}$ & $\mathrm{S}, 88$ & 35,19 & 23,33 & 0,73 & 0,93 \\
\cline { 2 - 7 } & $\mathrm{S}$ & 98,12 & $-1,84$ & 0,57 & 0,68 & 0,97 \\
\hline Nicosulfuron & $\mathrm{R}$ & 96,28 & 42,25 & 43,46 & 1,74 & 0,94 \\
& $\mathrm{~S}$ & 97,23 & 3,16 & 0,25 & 1,80 & 0,98 \\
\hline Metsulfuron-methyl & $\mathrm{R}$ & 97,73 & 25,46 & 13,22 & 1,12 & 0,93 \\
\cline { 2 - 7 } & $\mathrm{S}$ & 95,68 & 1,89 & 0,23 & 1,58 & 0,98 \\
\hline Imazethapyr & $\mathrm{R}$ & 95,25 & 49,99 & 44,02 & 3,46 & 0,95 \\
\hline & $\mathrm{S}$ & 95,74 & 5,62 & 0,77 & 1,35 & 0,97 \\
\hline
\end{tabular}

Tabela 3 - Resultados dos valores de $C_{50}$ do biótipo de B. pilosa resistente $(R)$ e suscetível (S) aos herbicidas chlorimuronethyl, nicosulfuron, metsulfuron-methyl e imazethapyr, e relação R/S.

\begin{tabular}{|c|c|c|c|}
\hline Herbicida & Resistente (R) & Suscetível (S) & $\mathrm{R} / \mathrm{S}$ \\
\hline Chlorimuron-e thyl & 466,60 & 11,40 & 40,92 \\
\hline Nicosulfuron & 2173,00 & 12,50 & 173,84 \\
\hline Me tsulfuron-me thyl & 39,66 & 0,69 & 57,47 \\
\hline Imazethapyr & 4402,00 & 77,00 & 57,16 \\
\hline
\end{tabular}

$\mathrm{C}_{50}=$ dose do herbicida em gramas do ingrediente ativo por hectare necessário para proporcionar $50 \%$ de controle da planta daninha. $R / S=$ divisão do $C_{50}$ do biótipo $R$ pelo $C_{50}$ do biótipo $S$.

Tabela 4 - Resultados dos valores de $C_{50}$ do biótipo de B. pilosa resistente (R) e suscetível (S) aos herbicidas chlorimuronethyl, nicosulfuron, metsulfuron-methyl e imazethapyr, e relação R/S correspondente à divisão do $\mathrm{C}_{50}$ do biótipo resistente pelo $\mathrm{C}_{50}$ do biótipo suscetível.

\begin{tabular}{lccc}
\hline Herbicida & Resistente $(\mathrm{R})$ & Suscetível $(\mathrm{S})$ & $\mathrm{R} / \mathrm{S}$ \\
\hline Chlorimuron-ethyl & 466,60 & 11,40 & 40,92 \\
Nicosulfuron & 2173,00 & 12,50 & 173,84 \\
Metsulfuron-methyl & 39,66 & 0,69 & 57,47 \\
Imazethapyr & 4402,00 & 77,00 & 57,16 \\
\hline
\end{tabular}

$\mathrm{C}_{50}=$ dose do herbicida em gramas do ingrediente ativo por hectare necessário para proporcionar $50 \%$ de controle da planta daninha.

Scientia Agricola, v.59, n.3, p.513-519, jul./set. 2002 

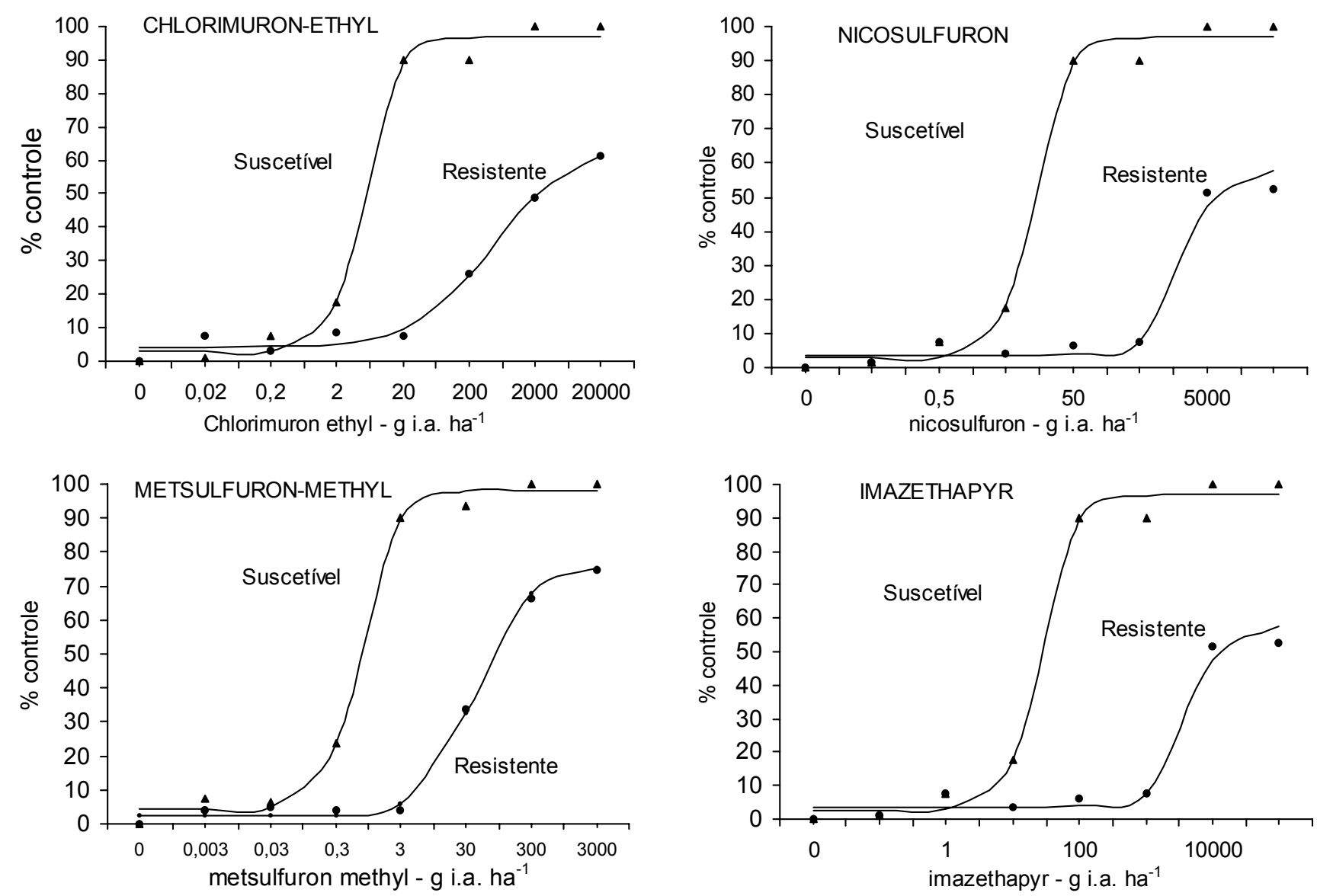

Figura 1 - Curva de dose-resposta da porcentagem de fitotoxicidade dos biótipos resistente (R) e suscetível (S) de $B$. pilosa com os herbicidas chlorimuron-ethyl, nicosulfuron, metsulfuron-methyl e imazethapyr usando o modelo log-logístico.

partir destes gráficos pode-se observar a diferença de porcentagem de fitotoxicidade entre os dois biótipos, verificando-se que o biótipo $\mathrm{R}$ não atinge $100 \%$ fitotoxicidade de mesmo em doses altas, bastante acima da recomendada. O biótipo resistente não foi controlado totalmente por nenhum dos herbicidas, mesmo em altas doses, porém este fato deve se a limitação das doses utilizadas no experimento.

Os testes de paralelismo das curvas de doseresposta não foram suficientemente confiáveis para concluir se o biótipo $\mathrm{R}$ de $B$. pilosa estudado tem como mecanismo de resistência à alteração no sítio de ação dos herbicidas inibidores da ALS. O biótipo R de B. pilosa tem resistência cruzada aos herbicidas do grupo químico das sulfoniluréias (chlorimuron-ethyl, nicosulfuron e metsulfuron-methyl) e ao herbicida do grupo das imidazolinonas (imazethapyr).

\section{AGRADECIMENTOS}

Ao Departamento de Produção Vegetal da Escola Superior de Agricultura "Luiz de Queiroz" Universidade de São Paulo, e ao Conselho Nacional de Desenvolvolvimento Científico e Tecnológico (CNPq) pelo apoio financeiro.

\section{REFERÊNCIAS BIBLIOGRÁFICAS}

BOUTSALIS, P.; POWLES, S.B. Resistance of dicot weeds to acetolactate synthase (ALS) inhibiting herbicides in Australia. Weed Research, v.35, p.149-155, 1995.

CAREY, J.B.; PENNER, D.; KELLS, J.J. Physiological basis for nicosulfuron and primisulfuron selectivity in five plant species. Weed Science, v.45, p.22-30, 1997.

CAUSTON, D.R.; ELIAS, C.O.; HADLEY, P. Biometrical studies of plant growth. I. The Richards function and its application in analyzing the effects of temperature on leaf growth. Plant Cell Evironm, v.1, p.163-184, 1978.

CHAVES, L.; VALVERDE, B.E.; GARITA, I. Resistance of Ixophorus unisetus to acetolactate synthase inhibiting herbicides. Manejo Integrado de Pragas, n.44, p.20-25, 1997.

CHRISTOFFOLETI, P.J.; PONCHIO, J.A.R.; BERG, C.V.D.; VICTORIA FILHO, $\mathrm{R}$. Imidazolinone resistant $B$. pilosa biotypes in the Brazilian soybean areas. In: 1996 MEETING OF THE WEED SCIENCE SOCIETY OF AMERICA, Norfolk, 1996. Abstract. Norfolk, 1996, v.36, p.10.

FRANCE, J.; THORNLEY, J.H.M. Mathemathical models in agriculture. Kent: Butherworths, 1984. 335p.

FRIESEN, L.F.; MORRISON, I.N.; RASHID, A.; DEVINE, M.D. Response of a chlorosulfuron resistant biotype of Kochia scoparia to sulfonylurea and alternative herbicides. Weed Science, v.41, p.100-106, 1993.

GUTTIERI, M.J.; EBERLEIN, C.V.; MALLORY-SMITH, C.A.; THILL, D.C.; HOFFMAN, D.L. DNA sequence variation in domain $A$ of the acetolactate synthase genes of herbicide resistant and susceptible weed biotypes. Weed Science, v.40, p.670-676, 1992.

HALL, L.M.; STROMME, K.M.; HORSMAN, G.P. Resistance to acetolactate synthase inhibitors and quinclorac in a biotype of false cleavers (Galium spurium). Weed Science, v.46, p.390-396, 1998.

HART, S.E.; SAUNDERS, J.W.; PENNER, D. Semidominant nature of monogenic sulfonylureia herbicide resistance in sugarbeet (Beta vulgaris). Weed Science, v.41, p.317-324, 1993.

HUNT, R. Plant growth curves, the functional approaches to plant growth analysis. Sheffield: Edward Arnold, 1982. 246p. 
LOVELL, S.T.; WAX, L.M.; SIMPSON, D.M.; McGLAMERY, M. Using in vivo acetolactate synthase (ALS) assay for identifying herbicide-resistant weeds. Weed Technology, v.10, p.936-942, 1996.

PONCHIO, J.A.R. Resistência de B. pilosa aos herbicidas inibidores da enzima acetolactato sintase. Piracicaba, 1997. 139p. Tese (Doutorado) - Escola Superior de Agricultura "Luiz de Queiroz", Universidade de São Paulo.

PONCHIO, J.A.R.; CHRISTOFFOLETI, P.J.; MELO, M.; VICTORIA FILHO,

R. ALS enzyme assay from B. pilosa biotypes of the Brazilian areas to determine the sensitivity to imidazolinone and sulfonylurea herbicides. In: 1996 MEETING OF THE WEED SCIENCE SOCIETY OF AMERICA, Norfolk, 1996. Abstract. Norfolk, 1996. p.79.

PORNPROM, T.; YONG, P.J. Assessment of ALS-inhibiting herbicide tolerance in pepper cultivars. Weed Science, v.17, p.325-333, 1997.

RYAN, G.F. Resistance of common groundsel to simazine and atrazine. Weed Science, v.18, p.614-620, 1970.

SAARI, L.L.; COTTERMAN, J.C.; PRIMIANI, M.M. Mechanism of sulfonylurea resistance in the broadleaf weed Kochia scoparia. Plant Physiology, v.93, p.55-65, 1990
SEEFELDT, S.S.; JENSEN, S.E.; FUERST, E.P. Log-logistic analysis of herbicide dose-response relationship. Weed Technology, v.9, p.218-227, 1995.

SHANER, D.L. Mechanisms of resistance to acetolactate synthase acetohydroxyacid synthase inhibitors. In: CASELEY, J.C.; CUSSANS, G.W.; OATKIN, R.K. Herbicide resistance in weeds and crops. Oxford: Buttlerworth-Heinemann, 1991. p.187-198.

SIMPSON, D.M.; STOLLER, E.W.; WAX, L.M. An in vivo acetolactate synthase assay. Weed Technology, v.9, p.17-22, 1995.

STREIBIG, J.C.; RUDEMO, M.; JENSEN, J.E. Dose-response curves and statistical models. In: STREIBIG, J.C; KUDSK, P. (Ed.) Herbicide bioassay. Boca Raton: CRC Press, 1993. p.30-35.

TRUELOVE, B.; HENSLEY, J.R. Methods of testing for herbicide resistance. In: LeBARON, H.; GRESSEL, J. (Ed.) Herbicide resistance in plants New York: John Willey \& Sons, 1982. chap.7, p.117-131.

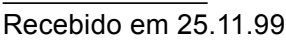

